such spasm. The difficulty then is to keep the eyes closed, and any, even the slightest, effort to open them is easily performed. During the acute stage of inflammation of any other joint there is encountered the same muscular contraction, and in the same way when all inflammation has disappeared from it the muscles which before were tonically contracted relax, and the difficulty is not to move the joint but by any means to keep it still. And it is by this sign, and by this sign alone, that the surgeon can be sure that it is safe now to use passive motion, if, indeed, in a joint which has suffered from simple synovitis and has been so treated passive motion is ever really required.

All treatment, then, of closed joints, as of the one open to observation, during the acute stage of simple inflammation should be directed towards the perfecting of nature's own remedy-that of rest. As he knows that of all the muscles around any joint, all of which are contracting in this way, the flexors will sooner or later obtain the advantage, the medical man arranges his apparatus so as to maintain an equilibrium and prevent any deformity which might arise by their excessive action. As he knows that muscles, though strong, are capable of becoming tired, and, especially when sleep overpowers the patient, of being momentarily relaxed, so permitting of slight movements in, and jars to, the inflamed surfaces, he assists their action by rigid appliances which shall supplement or, if necessary, be substitutes for them. But all this has been said, and said much better, by Hugh Owen Thomas and his successor, Mr. Robert Jones, to whose works, which are worth most careful study, I would refer all interested in this subject. My only object is to point out what I believe has not been previously noted-the presence before the surgeon's eyes of an open joint in which he may verify for himself the truth or otherwise of various doctrines with reference to the treatment of those other closed joints about which so much mystery has been made, and as to the exact condition of which so much doubt and paralysing uncertainty have existed, and still exist, in the minds of many surgeons.

Manchester.

\section{CASE OF REMOVAL OF THE SCAPULA AND UPPER EXTREMITY FOR SARCOMA.}

BY G. C. HALL, F.R.C.S.,

SORGEON-LIEDTENANT-COLONEL, INDIAN MEDICAL SERVICE, BENGAT.

THE patient, a beggar, had been wandering about the country carrying an enormous tumour the surface of which

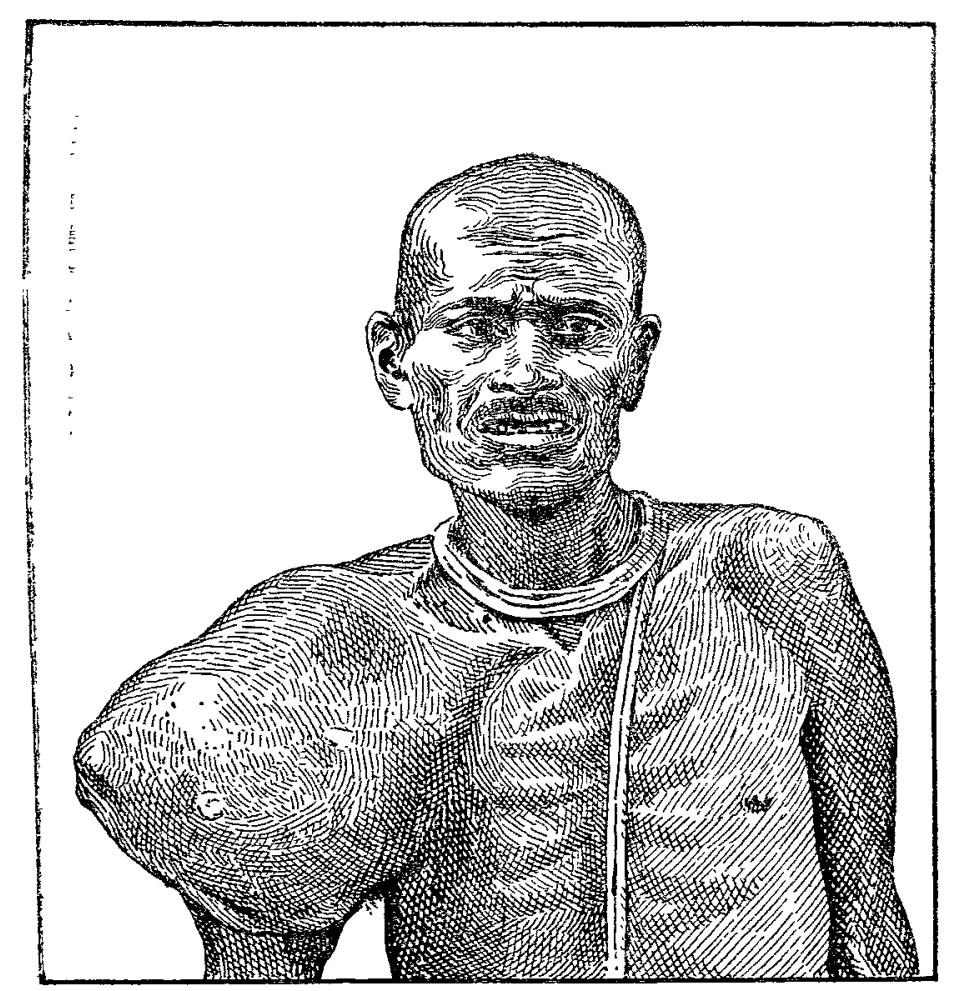

was ulcerated in places, on which numerous flies found a feeding ground. He had been rejected as a hospital case by numerous dispensary assistant surgeons and others, and had determined to take his life by drowning himself in the River Jumna. I therefore thought that he should at least have the chance offered by surgical intervention, and I decided to try to remove the tumour. His physical condition was as bad as it could be. I chloroformed him carefully, and began by making a posterior skin flap, securing the vessels en route, and loosened the attacliment of the scapula. I then attacke

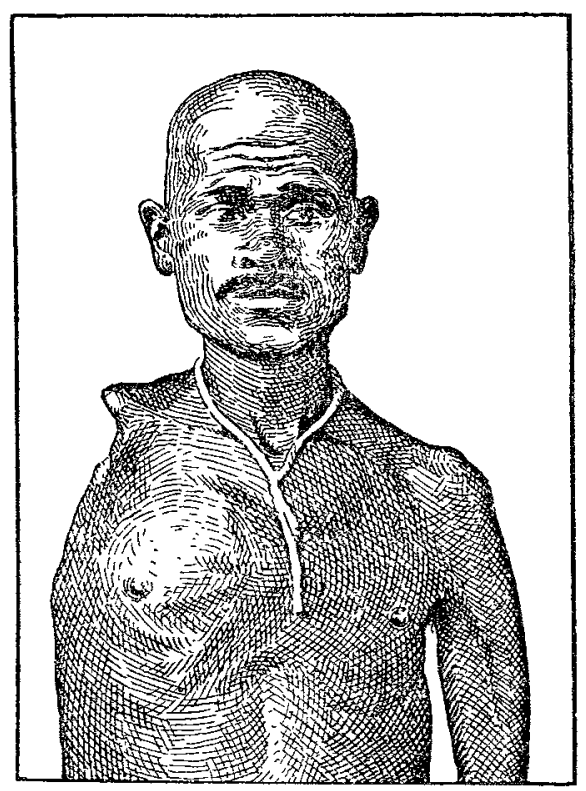

the front and tied the subclavian artery and found that the tumour had no attachment to the thorax, as had been thought to be the case. I then disarticulated the clavicle from the scapula, and removed the limb. He had no bad symptoms; he made a rapid recovery, and went to bathe in the Ganges and thank his special deity for favour vouch-

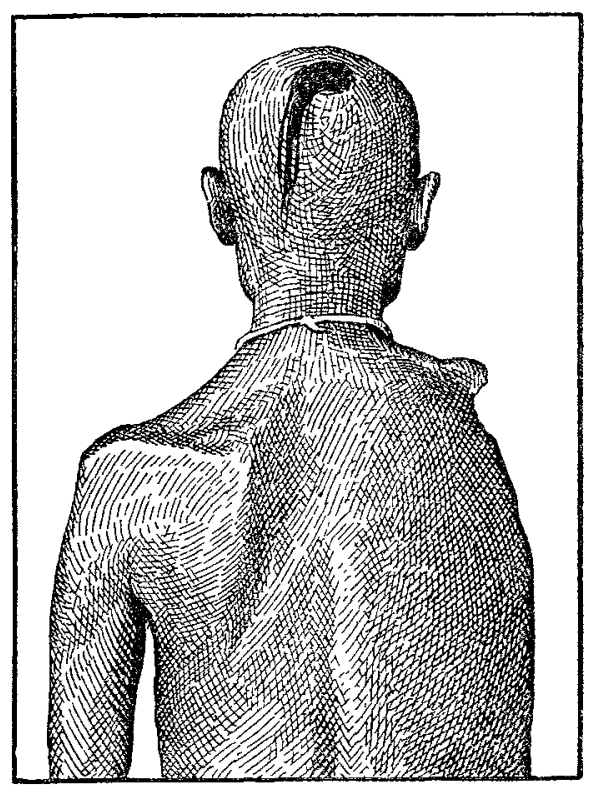

safed to him, having his mind firmly made up that as $I$ had removed his arm I would have to support him for the rest of his life. The gratitude of the Indian beggar is well known. The illustrations, which are from photographs, represent the condition of the patient before and after the operation.

Allahabad, India.

\section{THE INFLUENCE OF INHERITANCE ON THE TENDENCY TO HAVE TWINS.}

BY R. A. BREMNER, L.R.C.P. LoNo., M.R.C.S. ENG.

IN continuation of the recent articles on the tendency to twin births ${ }^{1}$ I send the following family history, which is vouched for by more than one of the relatives. I attended the mother of the last pair of twins, herself one of twins. 